\title{
Specialized Transduction of Kanamycin Resistance in a Providence Strain
}

\author{
By J. N. COETZEE \\ Department of Microbiology, University of Pretoria, South Africa
}

(Received 5 November I974)

\begin{abstract}
SUMMARY
Properties of a transducing system with a phage able to transduce a kanamycinresistance marker of the $\mathrm{T}$ compatibility group plasmid $\mathrm{R} 394$ at a frequency of $2 \times \mathrm{IO}^{-2} /$ plaque-forming unit adsorbed are described. The phage was detected in Providence strain P29 transduced to kanamycin resistance by Providence phage PL25 grown on this strain harbouring the R factor. Four P29 transductants, specially selected at the lowest multiplicities of infection of the high frequency transducing (HFT) phage, were defective lysogens. They plated PL25 with an efficiency of I and only one liberated low-titre phage spontaneously or on u.v. induction. The defect in maturation function could be corrected by introduction of a wild PL25 prophage. The transducing phage was serologically identical to PL25. It could transduce in single infection, but transduction frequency was increased by the simultaneous presence of homologous non-transducing phage. Transductants did not transfer the kanamycin-resistance marker by conjugation, and produced kanamycin-sensitive segregants at a moderate rate. These segregants could be transduced to kanamycin resistance by the HFT phage. Irradiation of HFT lysates by u.v. produced an exponential fall in transduction frequency. It was concluded that the defective phage transduced by lysogenization. Kanamycinresistant transductants could themselves be transduced to streptomycin resistance by PL25 reared on a streptomycin-resistant mutant. Lysogenic transductants produced by the HFT phage did not always liberate HFT phage on u.v. induction. Possible explanations are considered.
\end{abstract}

\section{INTRODUCTION}

Transduction of a Proteus rettgeri R factor R394 (Coetzee, Datta \& Hedges, 1972) by vector phage 34 (Coetzee \& Sacks, 1960) to Proteus mirabilis strain PM5006 yielded some transductants which only registered the kanamycin-resistance marker of the plasmid and could not transmit the marker by conjugation. The latter transductants were lysogenic and liberated phage able to transduce kanamycin resistance to PM5006 at a frequency of $3 \times 10^{-2}$ / plaque-forming unit (p.f.u.) adsorbed (Coetzee, 1974b). Transfer of R394 to these transductants yielded some progeny which, on u.v. induction, produced lysates that could transduce markers of kanamycin and ampicillin resistance at frequencies of $4 \times 10^{-2} / p . f . u$. adsorbed (Coetzee, 1975). Apart from the additional marker of the latter phage, properties of the two high frequency transducing (HFT) phages were similar. They were serologically identical to phage 34 and could transduce at a multiplicity of infection (m.o.i.) of less than $0.0 \mathrm{I}$. Transduction frequencies were increased about tenfold by the presence of homologous non-transducing phage. HFT lysates could also transduce various chromosomal markers at low frequencies. Transductants produced kanamycin-sensitive lysogenic segregants at high rates. Strain PM5006 is cryptically lysogenic (Krizsanovich, 1973) for a phage 
Table I. Bacteria, plasmids and phage

Bacteria

Providence P29

P29(PL25)

P29str-r

P29rou-I

P29arg-I

P29met-I

P29ura-I

Escherichia coli J53-I

Plasmids and hosts P29(R394)

P29( $\overline{\text { R394 })-0 ~}$

Bacteriophage

PL25·P29

PL25.P29str-r

PL25.P29(R394)
Properties*

Providence strain NCTC92 I I biogroup I.

Recipient for general transducing phage PL25.

Resistant to A

Strain P29 lysogenized with PL25

Resistant to I mg streptomycin sulphate/ml

Spontaneous rough colonial variant

Auxotrophic mutants produced by NTG treatment

Nalidixic acid-resistant mutant of $\mathbf{5} 53$, an $\mathrm{F}^{-} l a c^{+}$, pro, met mutant of E. coli $\mathrm{KI} 2$

Strain P29 with R plasmid R394 introduced by conjugation. $\mathrm{R} 394$ is a $\mathrm{T}$ compatibility group plasmid with markers $\mathrm{A}, \mathrm{K}$

Original transductant clone produced at high m.o.i. Superior line indicates that R394 was introduced by transduction with vector phage PL25

General transducing phage for P29

Produced by lytic infection of P29str- $r$ with PL25

Produced by lytic infection of P29(R394) with PL25
Reference

Coetzee (1974a); Coetzee

et al. (I966)

Coetzee et al. ( 1966$)$

Coetzee et al. (1966)

Coetzee (unpublished)

Coetzee (unpublished)

Clowes \& Hayes (1968);

Coetzee et al. (1972)

Coetzee (unpublished);

Coetzee et al. (1972)

Coetzee (unpublished)

* Symbols designate resistancce to: A, ampicillin; K, kanamycin.

morphologically and serologically identical to phage 34 , and many features of the transduction systems were explicable in terms of interaction between resident cryptic prophage and the HFT phage.

Organisms of the Providence group may be readily distinguished from $P$. mirabilis by simple biochemical tests but they have properties in common, and the tendency has been to arrange Providence in the Proteus-Providence group (see Coetzee, 1972; Prozesky et al. 1973). Generalized transducing phages for certain strains of Providence have been described (Coetzee, Smit \& Prozesky, 1966). During an investigation (Coetzee, unpublished) of R factor transduction by one of these phages (PL25) to strain NCTC92I I (re-named P29) it was found that transductants which had received the kanamycin-resistance marker of R394 were unable to transmit their antibiotic resistance by conjugation. It meant that the transmissibility system of the R factor was defective in Providence P29 or that the markers in question had integrated in another replicon which was not capable of conjugal transfer. This was reminiscent of the $P$. mirabilis systems just described. Non-homologous genes were being transduced and chances of recombination with the recipient chromosome were therefore reduced. This report deals with an investigation of the possibility that transductants were produced by phages carrying resistance genes and still able to lysogenize.

\section{METHODS}

Bacteria, plasmids and phages. These are listed in Table I.

Media. Media were as described previously (Coetzee et al. 1973) except that the minimal medium was that of Lederberg (1950). Selection for drug resistance was on MacConkey agar containing one or more of the following: ampicillin, kanamycin, nalidixic acid and 
Table 2. Transductions by u.v.-induced lysate of $\mathrm{P} 29(\overline{R 394})-\mathrm{o}$ and by phage PL25·P29str-r

\begin{tabular}{|c|c|c|c|c|c|}
\hline & \multirow[b]{2}{*}{$\begin{array}{c}\text { Titre } \\
\text { (p.f.u./ml) }\end{array}$} & \multirow[b]{2}{*}{$\begin{array}{l}\text { Multiplicity } \\
\text { of infection }\end{array}$} & \multirow[b]{2}{*}{ Recipient } & \\
\hline Lysate & & & & $\begin{array}{c}\text { Kanamycin } \\
\text { resistant }\end{array}$ & $\begin{array}{l}\text { Streptomycin } \\
\text { resistant }\end{array}$ \\
\hline \multirow{2}{*}{$\begin{array}{l}\text { U.v.-induced } \\
\text { P29 }(\overline{R 394})-0\end{array}$} & $6 \times 10^{7}$ & $10^{-6}$ & P29 & $4 \times 10^{-2}$ & - \\
\hline & & $10^{-3}$ & P29rou-I & $5 \times 10^{-4}$ & - \\
\hline \multirow[t]{3}{*}{ PL25.P29str-r } & $\mathrm{I} \times 1 \mathrm{IO}^{9}$ & $10^{-1}$ & & - & $5 \times 10^{-7}$ \\
\hline & & $10^{\circ}$ & P29rou-I & - & $<2 \times 10^{-8}$ \\
\hline & & $10^{-1}$ & P29 (394)-O & - & $\mathrm{I} \times 10^{-7}$ \\
\hline
\end{tabular}

streptomycin. Ampicillin, kanamycin and nalidixic acid were used at $50 \mu \mathrm{g} / \mathrm{ml}$ unless otherwise stated. Streptomycin was used at I $\mathrm{mg} / \mathrm{ml}$. Incubation temperature was $30{ }^{\circ} \mathrm{C}$.

Conjugal transfer of plasmids and preparation of lytic phage lysates. Methods were as described by Coetzee et al. (1973).

Phage neutralization. This was done according to the method of Adams (1956). The antiserum used was raised in a rabbit against phage PL25. It was stored freeze-dried, and had a $\mathrm{K}$ value of $120 / \mathrm{min}$ (Coetzee et al. 1966).

Determination of the stability of the kanamycin-resistance marker in $\mathbf{P} 29(\overline{R 394})$. This was done as described by Coetzee (1974b) with the exception that PL25 antiserum $(K=60)$ was substituted.

Ultraviolet irradiation of phage and phage induction. This was done as described (Coetzee, I974b).

Concentration of phage lysates. The method described for $\mathrm{P}_{22}$ by Yamamoto \& Alberts (1970) was used.

Replica screening technique for detection of HFT phage and standard transduction experiments. These were done exactly as described by Coetzee (1974b). Briefly, adsorption mixtures were filtered and membranes with impinged bacteria were incubated on nutrient agar for $\mathrm{I} \mathrm{h}$ before transfer to MacConkey agar containing $50 \mu \mathrm{g}$ kanamycin $/ \mathrm{ml}$. For streptomycin resistance, membranes were maintained on agar for $4 \mathrm{~h}$ before transfer to MacConkey agar containing I mg streptomycin/ml.

\section{RESULTS}

Providence strain P29 is naturally resistant to ampicillin and sensitive variants have not been obtained (Coetzee, unpublished). Consequently only the kanamycin-resistance marker of R factor R394 could be selected. Sterile lysates prepared from strain P29(R394) with phage PL25 had titres of $5 \times 10^{9}$ p.f.u./ml and the lysates, designated PL25.P29(R394), transduced the kanamycin-resistance marker to $\mathrm{P} 29$ at a frequency of $5 \times 10^{-6} / \mathrm{p}$.f.u. adsorbed. The m.o.i. of the phage was about 2. Eight of Io transductant clones failed to transfer kanamycin (or ampicillin) resistance to Escherichia coli J53-I by conjugation. One of the eight clones was chosen for further study and designated P29 $\left(\overline{R_{394}}\right)-0$.

\section{Properties of transductant $\mathrm{P} 29\left(\overline{R_{394}}\right)-0$}

The conjugation with J53-I as recipient and $\mathbf{P} 29\left(\overline{\mathrm{R}_{394}}\right)$-0 as donor was repeated with selection for progeny on nalidixic acid plates (used for counterselection) and containing kanamycin or ampicillin. The crosses were sterile. Phage PL25 did not form plaques on P29 ( $\left(\overline{R_{394}}\right)-0$, and overnight broth cultures of the strain contained, per ml, about $\mathrm{I} \times \mathrm{IO}^{6}$ 
p.f.u. of a phage serologically identical to PL25 when assayed on P29. These titration plates were replicated to kanamycin agar which was then incubated overnight. The replicas, especially of the lower dilution plates, showed practically confluent growth. This has been described as a screening method for phage capable of high frequency transduction of antibiotic resistance (Coetzee, $1974 b$ ). Induction of the strain by u.v. irradiation yielded a lysate with a titre of about $6 \times 10^{7}$ p.f.u. $/ \mathrm{ml}$. The lysate was capable of HFT of the kanamycin marker at a m.o.i. of ${ }^{10^{-6}}$ (Table 2). Minute colonies suggestive of abortive transduction were not observed. The number of transductant clones which appeared on membranes transferred to agar containing $50 \mu \mathrm{g}$ kanamycin $/ \mathrm{ml}$ immediately after filtration at the end of the adsorption period, could not be increased by prior incubation on non-selective media. It was concluded that $\mathbf{P 2} 9$ expressed resistance to this concentration of kanamycin immediately after the termination of phage adsorption. Membranes had to be incubated for about $\mathrm{I} h$ on non-selective agar for transductants to achieve full resistance to $500 \mu \mathrm{g}$ kanamycin $/ \mathrm{ml}$. A similar situation was encountered with the $P$. mirabilis HFT phage for kanamycin resistance (Coetzee, $\mathrm{I} 974 b$ ). Strain P29 $(\overline{\mathrm{R} 394})$-o could be transduced to streptomycin resistance by PL25.P29str-r (Table 2). This is in accord with findings (Coetzee et al. 1966) that auxotrophs of P29 could be transduced to prototrophy and the prototrophs could then be transduced to streptomycin resistance by the above phage. A rough mutant of P29 which could not be transduced to streptomycin resistance by the general transducing phage (Table 2) could be transduced to kanamycin resistance by the HFT lysate at a lower frequency than usual. This could be due to the rough mutant adsorbing phage so poorly that only HFT phage could register its marker. Four kanamycin-resistant clones produced by the infection of P29 at a m.o.i. of $10^{-6}$ in the presence of PL25 antiserum and designated P29 $\left(\overline{R_{394}}\right)$ I to 4 were chosen for further study.

\section{Properties of $\mathrm{P} 29\left(\overline{R_{394}}\right)$ I to 4}

The four clones resembled $\mathrm{P} 29(\overline{\mathrm{R} 394})-\mathrm{O}$ in antibiotic resistance and did not transmit resistance by conjugation to $E$. coli $\mathrm{J} 53$-I. They differed from the original transductant in that only one (No. 4) liberated phage spontaneously or on u.v. induction and then only in low titre (approx. 50 p.f.u./ml), and all four plated PL25 with an efficiency of I. Unlike P29( $(\overline{\mathrm{R} 394})$-O these transductants were selected at low m.o.i. and arose in the presence of phage antiserum. They probably resulted from single particle infection, and the abovementioned properties suggested defective immunity and maturation functions of the transducing phage. The four transductants segregated kanamycin-sensitive clones (designated $\left.\mathrm{P} 29\left(\overline{\mathrm{R}_{394}}\right) \mathrm{K}^{\mathrm{s}}\right)$ at about $\mathrm{I} \times \mathrm{IO}^{-4} /$ bacterium/generation. Segregants were fully sensitive to PL25 and did not liberate phage. The rate of segregation of the marker is evidence that transduction proceeded by lysogenization (Luria, Adams \& Ting, 1960). These four transductants, like $\mathrm{P} 29(\overline{\mathrm{R}} 394)-0$, could be transduced to streptomycin resistance by phage PL25.P29str-r (not shown). Turbid centres of the PL25 plaques on the four kanamycinresistant transductants $\mathrm{P} 29\left(\overline{\mathrm{R}_{394}}\right)$ I to 4 were streaked on kanamycin agar, and single clones corresponding to each transductant, lysogenic for PL25, were obtained. These were designated P29( $\overline{\mathrm{R} 394} \mathrm{PL} 25)$ I to 4 .

\section{Properties of P29 $(\overline{R 394} P L 25)$ I to 4}

These strains differed from P29 $(\overline{\mathrm{R} 394})$ I to 4 in that they did not plate PL25 and liberated phage spontaneously which was serologically identical to PL25. They could however be transduced to streptomycin resistance by phage PL25.P29str-r, and gave rise to kanamycinsensitive lysogenic segregants (designated P29 $(\overline{\mathrm{R} 394} \mathrm{PL} 25) \mathrm{k}^{\mathrm{s}}$ ) at a frequency of about 
Table 3. Transduction with u.v.-induced lysates of $\mathrm{P} 29(\overline{R 394} P L 25)$ I to 4

\begin{tabular}{|c|c|c|c|c|}
\hline $\begin{array}{l}\text { Strain from which } \\
\text { lysate was induced }\end{array}$ & $\begin{array}{c}\text { Titre } \\
\text { (p.f.u./ml) }\end{array}$ & $\begin{array}{l}\text { Multiplicity of } \\
\text { infection }\end{array}$ & Recipient & $\begin{array}{l}\text { Kanamycin-resistant } \\
\text { (or prototrophic) } \\
\text { transductants*/p.f.u. } \\
\text { adsorbed }\end{array}$ \\
\hline $\begin{array}{r}\text { P29( } \overline{\mathrm{R} 394} \mathrm{PL} 25)-\mathrm{I} \\
2 \\
3 \\
4\end{array}$ & $\begin{array}{l}6 \times 10^{6} \\
8 \times 10^{7} \\
1 \times 10^{7} \\
3 \times 10^{7}\end{array}$ & $\begin{array}{l}10^{-6} \\
10^{-6} \\
10^{-4} \\
10^{-3}\end{array}$ & $\begin{array}{l}\text { P29 } \\
\text { P29 } \\
\text { P29 } \\
\text { P29 }\end{array}$ & $\begin{array}{l}2 \times 10^{-2} \\
1 \times 10^{-2} \\
1 \times 10^{-4} \\
8 \times 10^{-6}\end{array}$ \\
\hline P29 $(\overline{\mathrm{R} 394} \mathrm{PL} 25)-\mathrm{I}$ & $6 \times 10^{6}$ & $10^{-6}$ & P29(PL25) & $\mathrm{I} \times \mathrm{IO}^{-3}$ \\
\hline $\mathrm{P} 29(\overline{\mathrm{R} 394} \mathrm{PL} 25)-2$ & $\begin{array}{l}\mathrm{I} \times \mathrm{IO}^{9} \\
\mathrm{I} \times \mathrm{IO}^{9} \\
\mathrm{I} \times \mathrm{IO}^{9}\end{array}$ & $\begin{array}{l}10^{-1} \\
10^{-1} \\
10^{-1}\end{array}$ & $\begin{array}{l}\text { P29arg-I } \\
\text { P29met }-\mathrm{I} \\
\text { P29ura-I }\end{array}$ & $\begin{array}{l}<5 \times 10^{-8} \\
<5 \times 10^{-8} \\
<5 \times 10^{-8}\end{array}$ \\
\hline P29 $\left(\overline{R_{394}}\right.$ PL25)-I & $\begin{array}{l}6 \times 10^{6} \\
6 \times 10^{6}\end{array}$ & $\begin{array}{l}10^{-6} \\
10^{-6}\end{array}$ & $\begin{array}{l}\text { P29 }\left(\overline{\mathrm{R}_{394}}\right) \mathrm{k}^{\mathrm{S}} \\
\text { P29 }\left(\overline{\mathrm{R}_{394}} \mathrm{PL}_{25}\right) \mathrm{k}^{\mathrm{S}}\end{array}$ & $\begin{array}{l}1 \times 10^{-2} \\
5 \times 10^{-4}\end{array}$ \\
\hline
\end{tabular}

* Kanamycin-resistant transductions were as described in Methods. The phages used for prototrophic transductions were concentrated and membranes with impinged cells were placed on minimal medium immediately after filtration.

$\mathrm{I} \times \mathrm{IO}^{-4} /$ bacterium/generation. Induction by u.v. irradiation yielded lysates with titres of $6 \times 10^{6}$ to $8 \times 10^{7}$ p.f.u. $/ \mathrm{ml}$. Lysates invariably contained an unusually high proportion (up to $10 \%$ of particles which produced clear plaques on P29. Some of these clear and turbid plaques were picked off and used to prepare separate lysates of P29 $(\overline{R 394})-I$, the first of the four transductant clones produced at low m.o.i. The lysates transduced P29 to kanamycin resistance at a frequency of about $2 \times \mathrm{IO}^{-9} / \mathrm{p}$.f.u. adsorbed (not shown). It is probable therefore that kanamycin-resistance transduction by HFT phage was effected by non-plaque forming particles (see Smith-Keary, 1966). Lysates induced by u.v. irradiation of strains P29( $\overline{\mathrm{R} 394} \mathrm{PL} 25) \mathrm{I}$ to 4 differed in their transduction frequencies for kanamycin resistance (Table 3). The reason is not understood. The producer strains were similar in all other respects and lysates had comparable plaque-forming titres. This variation in transduction frequency was also a variable property: further lysates prepared from strains which yielded low transducing frequency phage sometimes yielded phage with much higher transducing ability. Lysate P29(R394PL25)-2 (Table 3, line 2) had many more clear-plaque forming particles than the other lysates and so it was unlikely that results could be explained in terms of lysis of transductants by virulent phage.

\section{Transduction of ability to yield HFT lysates}

Seventeen transductant clones from experiments done simultaneously with those reported in Table 3 but produced at a m.o.i. of about 4 , and therefore lysogenic, were examined for ability to yield HFT phage on u.v. induction. Titres of the lysates varied from $5 \times 10^{6}$ to $7 \times 10^{7}$ p.f.u. $/ \mathrm{ml}$. Only ten of the lysates transduced at a frequency of about $2 \times 10^{-2} /$ p.f.u. adsorbed. The transduction frequencies of the remaining seven lysates varied between $4 \times 10^{-4}$ and $3 \times 10^{-5} /$ p.f.u. adsorbed.

These seven transductants segregated kanamycin-sensitive clones at the same rate as the other ten. Many other lysogenic transductants phenotypically identical to those mentioned above were tested during the course of this investigation. Failure to yield lysates with transduction frequencies above $\mathrm{I} \times 10^{-2} /$ p.f.u. adsorbed was quite a common, but variable, feature. 
The HFT phage was concentrated to $\mathrm{I} \times 1 \mathrm{I}^{9}$ p.f.u. $/ \mathrm{ml}$ and used in transduction experiments with various auxotrophs of P29 as recipients. Unlike the HFT phages described by Kondo \& Mitsuhashi (1964), Jessop (1972) and Coetzee (1974 b, 1975), lysates could not transduce other markers (Table 3 ). Results presented in Table 3 also indicate that P29(PL25) is transduced at a frequency about 20-fold lower than P29. If HFT transduction proceeds by lysogenization, then this could be explained on the grounds that, as the principal attachment site was occupied, transducing phage had to contend with less efficient secondary sites. Weigle (1957) and Hoppe \& Roth (1974) encountered similar phenomena with $\lambda d g$ and a P22 HFT lysate respectively. Transduction of phage-sensitive, as well as lysogenic kanamycinsensitive, segregants with HFT phage lysates revealed that the former were transduced at a frequency similar to wild-type $\mathbf{2 9}$ while with the latter the frequency was about 20-fold lower (Table 3). In contrast, generalized transduction (Table 2) was not affected to the same degree by recipients being lysogenic and this fact supported the thesis that HFT proceeded by lysogenization.

\section{Relatedness of PL25 and transducing particles of HFT lysates}

Samples of a HFT lysate derived from P29( $\left.\overline{\mathrm{R}_{394}} \mathrm{PL} 25\right)-\mathrm{I}$ (Table 3) were treated with dilutions of PL25 antiserum and plaque-forming and transducing activities of the lysate determined as a function of amount of antiserum added. Transducing activity was assayed in the presence of helper phage to ensure that diminished transducing activity was not due to loss of helper. The two parameters diminished at the same rate (Fig. I). This is evidence for the serological identity of the particles concerned and eliminates the possibility that the vector was a serologically different prophage present in P29.

\section{Defectiveness of HFT phage}

It was demonstrated (Tables 2 and 3 ) that the HFT phage could transduce at very low m.o.i. and it was probable that a single particle could transduce. Results presented in Fig. 2 again emphasize this point. The rapid fall of the curve for HFT alone (solid circles) between m.o.i. of $\mathrm{I}$ and $1 \mathrm{O}^{-2}$ (where chances of simultaneous infection by transducing and normal particles present in the lysate are slight) is not indicative of mutual aid between particles (Chan et al. 1972; see also Rae \& Stodolsky, 1974). The presence of helper phage, at a m.o.i. of 3 , increased the transduction frequency about fivefold.

\section{Effect of u.v. irradiation of HFT lysates on transduction}

A HFT lysate was irradiated for different periods of time. Samples were titrated and quantitative transduction experiments performed with each sample. The curves (Fig. 3) relating time of irradiation to transduction frequency and phage survival, showed exponential declines with the slope of the former about half that of the latter. This implies that some phage functions are not required for transduction. The slope of the transduction curve differs from that obtained when the frequency of streptomycin-resistance transduction was measured as a function of time of irradiation of PL25 (Coetzee et al. 1966) where an increase in transductants, at low doses, was followed by slow inactivation. The initial increase was attributed to greater frequency of recombination between chromosome and the exogenote (Arber, 1958; Luria et al. 1960). Arber (1960) demonstrated an exponential fall in numbers of transductants of various episomes with increasing doses of irradiation applied to transducing lysates, and Luria et al. (1960) ascribed the simple decline in numbers of $\mathrm{lac}^{+}$Shigella transductants produced by irradiation of PI lysates of $E$. coli to failure of the 


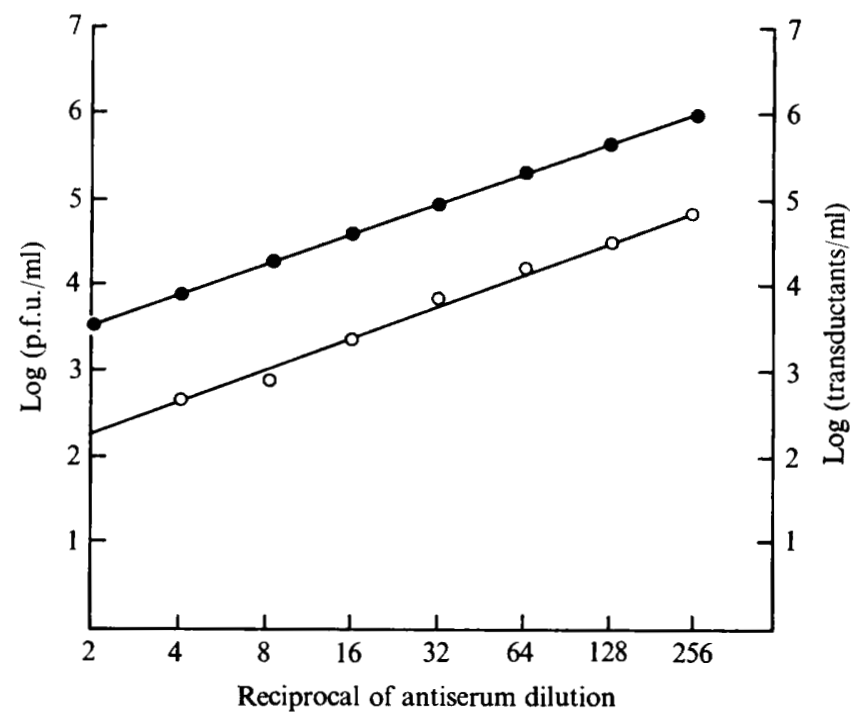

Fig. 1. Effect of phage PL25 antiserum on transduction frequency of a HFT lysate derived from P29(R394PL25)-I. One $\mathrm{ml}$ of serial twofold dilutions of phage PL25 antiserum in $0.85 \%(\mathrm{w} / \mathrm{v}) \mathrm{NaCl}$ were mixed with an equal volume of lysate and incubated for $5 \mathrm{~min}$. The p.f.u. titre of the samples was determined and then $0.5 \mathrm{ml}$ of phage PL25.P29 (titre $6 \times 10^{10}$ p.f.u./ml) was added to the samples and quantitative kanamycin-resistance transductions performed. Plaque-forming titre $/ \mathrm{ml} ; \bigcirc$, no. kanamycin-resistant transductants $/ \mathrm{ml}$.

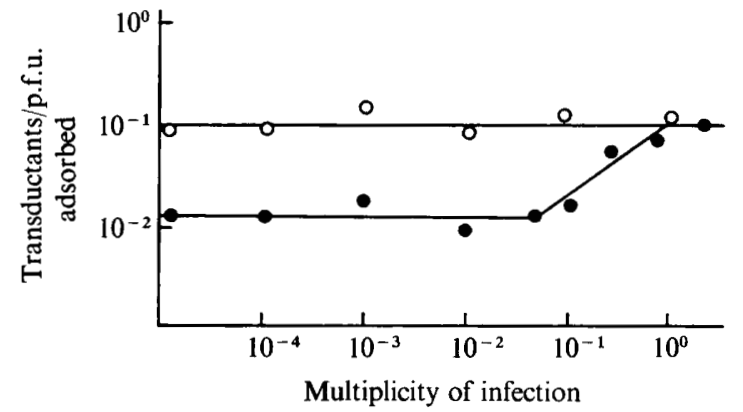

Fig. 2

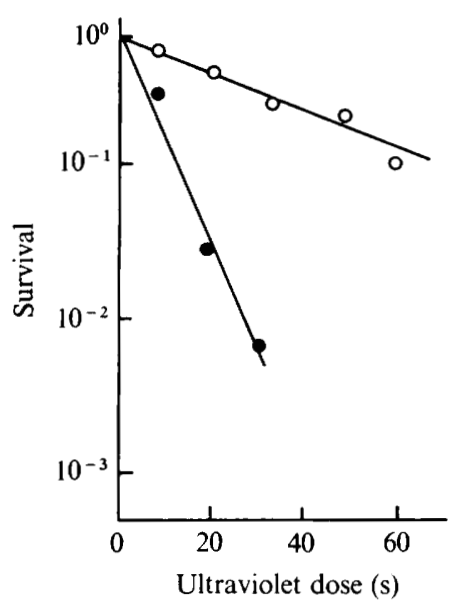

Fig. 3

Fig. 2. Effect of helper phage on efficiency of transduction. Transductions were with HFT lysate P29( $(\overline{\mathrm{R} 394} \mathrm{PL} 25)$-I at different m.o.i. Helper phage, PL25.P29str-r, was used at m.o.i. of 2.9., HFT phage; $C$, HFT phage and helper phage.

Fig. 3. The effect of u.v. irradiation on a HFT lysate. Quantitative transduction experiments were done with the irradiated lysates at a m.o.i. of I p.f.u. of the unirradiated phage. $\bigcirc$, Transducing activity; , plaque formation. 
particles to persist as prophages. A similar interpretation may apply here. This supports the contention, derived from the rate at which kanamycin-sensitive segregants arose and also from the disparity in the rates of HFT to lysogenic and non-lysogenic recipients, that the $\mathrm{R}$ factor genes formed part of the phage which transduced by lysogenization (Coetzee, $1974 b, \mathrm{I} 975)$.

\section{DISCUSSION}

Luria et al. (1960) were the first to employ transduction of non-homologous genes to select HFT phage capable of conveying the genes while retaining ability to lysogenize. This principle has been brilliantly exploited by Hoppe \& Roth (1974); see also Rae \& Stodolsky (1974). Specialized transducing phages vary in the complement of phage functions retained. There are the tet ${ }^{\mathrm{R}} \mathrm{P}_{22}$ (Chan et al. 1972) and PIdl (Rae \& Stodolsky, I974) phages which cannot multiply or lysogenize on single infection, the variants of phage epsilon (Kameda et al. 1965) and P22 (Hoppe \& Roth, 1974) which can lysogenize but exhibit no immunity or maturation functions, and the semi-defective particles of $\lambda d g$ and $\mathrm{P} 22$ which can lysogenize and retain immunity properties but possess no (Campbell, I957; Smith-Keary, I966) or virtually no (Dubnau \& Stocker, 1964) maturation function. Finally, there are converting phages PICM (Kondo \& Mitsuhashi, 1964) and $\phi$ Amp $^{+}$(Williams Smith, 1972) which retain all phage functions. The phage described here has many of the properties of the phage epsilon tetracycline-resistance HFT lysate described by Kameda et al. (1965). The latter particles could also transduce on single infection and were defective in immunity and maturation functions. They differed from the Providence phage in that helper phage did not affect transduction frequency. The helper effect encountered here may be explained as by Coetzee (1974 $b, 1975)$, that non-transducing phage supplied some function which increased the probability of successful lysogenization by transducing phage. It was shown that the HFT Providence phage was defective (amongst other functions) in maturation and this could be corrected by a normal prophage. A disturbing feature was the fact that though phage titres were comparable, the transduction frequencies of different lysates varied considerably. The defaulting lysates were unlikely to have arisen by double cross-over events with the chromosome as Matsushiro (1963) sometimes encountered with $\phi 80 d t$, as such an explanation is incompatible with the frequency of segregation of kanamycin-sensitive clones from all transductants tested (see Bernstein, Rolfe \& Onodera, I973). In addition, the Providence HFT phage was not capable of general transduction. A possible explanation is that a permutation of the excision event (Luria et al. 1960; Matsushiro, 1963; Rae \& Stodolsky, I974; see also Weigle, Meselson \& Paigen, 1959; Adler \& Templeton, 1963) of the prophage occurred in individual bacteria of a lysate and this resulted in individual vegetative phage genomes containing complete or defective portions of the kanamycinresistance gene. Watanabe et al. (1972) found that nine out of ten transductants obtained from a P22 HFT lysate for tetracycline resistance produced HFT lysates on u.v. induction. Schmieger (1972), Gratia (1973), Wall \& Harriman (1974) and Backhaus \& Schmieger (1974) have demonstrated that phage does not necessarily play the passive 'phenotypic mixing' role in general transduction previously (see Ozeki \& Ikeda, 1968) assigned to it and the possibility exists that PL25 acquired the kanamycin (and possibly ampicillin) genes from the $\mathrm{R}$ plasmid by integration of the $\mathrm{R}$ factor into the phage on the host chromosome.

Many PL25 lysates of P29 strains harbouring various $R$ factors have been screened (Coetzee, unpublished) and only lysates of P29 carrying R394 yielded HFT phage for antibiotic resistance. The antibiotic-resistance markers of $\mathrm{R} 394$ have also combined with the $P$. mirabilis transducing phage 5006M (Coetzee, $1974 b$, I975). It may be that this proclivity of 
R394 for recombination with phage genomes results from its resistance markers being contained in transposons (Hedges \& Jacob, 1974). Transposition on to vegetative, or prophage, genes could account for the missing phage functions, but the increased molecular weight of the genome could result in encapsidation problems. Physical characteristics of the genome of PL25 have not yet been determined but particles of the HFT phage can transduce on single infection. They thus differ from the particles of $\mathrm{P}_{22}$ tet $^{\mathrm{R}}$ and $\mathrm{P} I d l$ phages described by Chan et al. (1972) and Rae \& Stodolsky (1974), respectively, which must be complemented by another particle to achieve expression.

The author is in receipt of grants from the South African Medical Research Council.

\section{REFERENCES}

Adams, M. H. (1956). Methods of study of bacterial viruses. Methods in Medical Research 2, I-73.

Arber, W. (1958). Transduction des caractères gal par le bactèriophage lambda. Archives scientiae (Geneva) II, 259-338.

Arber, W. (1960). Transduction of chromosomal genes and episomes in Escherichia coli. Virology II, 273-288.

Adler, J. \& Templeton, B. (1963). The amount of galactose genetic material in $\lambda d g$ bacteriophage with different densities. Journal of Molecular Biology 7, $710-720$.

Backhaus, H. \& Schmieger, H. (I974). The origin of the DNA in a special class of generalized transducing particles of Salmonella-phage P22. Molecular and General Genetics 131, I 23-I 35.

Bernstein, A., Rolfe, B. \& Onodera, K. (1973). The $E$. coli cell surface: isolation of $\lambda$ transducing phages carrying the tolPAB cluster. Molecular and General Genetics 121, 325-335.

Campbell, A. (1957). Transduction and segregation in Escherichia coli KI 2. Virology 4, 366-384.

Chan, R. K., Botstein, D., Watanabe, T. \& OGata, Y. (I972). Specialized transduction of tetracycline resistance by phage $\mathrm{P} 22$ in Salmonella typhimurium. Virology 5o, 883-898.

Clowes, R. C. \& Hayes, W. (1968). Experiments in Microbial Genetics. Oxford and Edinburgh: Blackwell Scientific Publications.

Coetzee, J. N. (1972). Genetics of the Proteus group. Annual Review of Microbiology 26, 23-54.

Coetzee, J. N. (1974a). Properties of Proteus and Providence strains harbouring recombinant plasmids between P-lac and RIdrd 19 or R447b. Journal of General Microbiology 80, 1 19-130.

Coetzee, J. N. (1974b). High frequency transduction of kanamycin resistance in Proteus mirabilis. Journal of General Microbiology 84, 285-296.

CoetzeE, J. N. (1975). High frequency transduction of ampicillin and kanamycin resistance in Proteus mirabilis. Journal of General Microbiology 87, 173-1 76.

Coetzee, J. N., Datta, N. \& Hedges, R. W. (1972). R factors from Proteus rettgeri. Journal of General Microbiology 72, 543-552.

Coetzee, J. N., Datta, N., Hedges, R. W. \& Appelbaum, P. C. (1973). Transduction of R factors in Proteus mirabilis and P. rettgeri. Journal of General Microbiology $76,355^{-3} 68$.

Coetzee, J. N. \& Sacks, T. G. (1960). Transduction of streptomycin resistance in Proteus mirabilis. Journal of General Microbiology 23, 445-455.

Coetzee, J. N., Smit, J. A. \& Prozesky, O. W. (I966). Properties of Providence and Proteus morganii transducing phages. Journal of General Microbiology 44, I67-I 76.

Dubnau, E. \& Stocker, B. A. D. (1964). Genetics of plasmids in Salmonella typhimurium. Nature, London 204, I I I 2-I I I 3.

Gratia, J. P. (1973). Coliphage $\phi y$, a novel type of specialized transducer. Molecular and General Genetics I24, I 57-I 66.

Hedges, R. W. \& JACOB, A. E. (I974). Transposition of ampicillin resistance from RP4 to other replicons. Molecular and General Genetics $\mathbf{1 3 2}, 3 \mathrm{I}-40$.

Hoppe, I. \& Rотн, J. (1974). Specialized transducing phages derived from Salmonella phage P22. Genetics 76, 633-654.

Jessop, A.P.(1972). A specialized transducing phage of $\mathrm{P}_{22}$ for which the ability to form plaques is associated with transduction of the proAB region. Molecular and General Genetics II4, 2 I4-222.

Kameda, M., Harada, K., Suzuki, M. \& Mirsuhashi, S. (1965). Drug resistance of enteric bacteria. V. High frequency of transduction of $\mathrm{R}$ factors with bacteriophage epsilon. Journal of Bacteriology 90, I I 74-I I 8I. 
Kondo, E. \& Mitsuhashi, S. (I964). Drug resistance of enteric bacteria. IV. Active transducing bacteriophage PI CM produced by the combination of R factor with bacteriophage PI. Journal of Bacteriology 88, I 266-I 276.

Krizsanovich, K. (I973). Cryptic lysogeny in Proteus mirabilis. Journal of General Virology r9, 3 I I-320.

LEDERBERG, J. ( 1950 ). Isolation and characterization of biochemical mutants of bacteria. Methods in Medical Research 3, 5-I 8 .

Luria, S. E., Adams, J. N. \& TING, R. C. (I960). Transduction of lactose-utilizing ability among strains of $E$. coli and $S$. dysenteriae and the properties of the transducing phage particles. Virology 12, 348-390.

MAtsushiro, A. (1963). Specialized transduction of tryptophan markers in Escherichia coli KI 2 by bacteriophage $\phi$ 8o. Virology r9, 475-482.

Ozeki, H. \& IkedA, H. (1968). Transduction mechanisms. Annual Review of Genetics 2, 245-278.

Prozesky, O. W., Grabow, W. O. K., van der Merwe, S. \& Coetzee, J. N. (1973). Arginine gene clusters in the Proteus-Providence group. Journal of General Microbiology 77, 237-240.

RaE, M. E. \& Stodolsky, M. (I974). Chromosome breakage, fusion and reconstruction during PIdl transduction. Virology 58, 32-54.

SChmieger, H. (1972). Phage P22 mutants with increased or decreased transduction abilities. Molecular and General Genetics I19, 75-88.

Smith-Keary, P. F. (1966). Restricted transduction by bacteriophage $\mathbf{P}_{22}$ in Salmonella typhimurium. Genetic Research 8, 73-82.

Wall, J. D. \& Harriman, P. D. (1974). Phage PI mutants with altered transducing abilities for Escherichia coli. Virology 59, 532-544.

Watanabe, T., Ogata, Y., Chan, R. K. \& Botstein, D. (1972). Specialized transduction of tetracycline resistance by phage $\mathbf{P}_{22}$ in Salmonella typhimurium. I. Transduction of $\mathbf{R}$ factor 222 by phage $\mathbf{P}_{22}$. Virology 50, 874-882.

WeIGLE, J. (I957). Transduction by coliphage $\lambda$ of the galactose marker. Virology 4, 14-25.

Weigle, J., Meselson, M. \& Paigen, K. (I959). Density alterations associated with transducing ability in the bacteriophage lambda Journal of Molecular Biology I, 379-386.

Williams Smith, H. (1972). Ampicillin resistance in Escherichia coli by phage infection. Nature, London 238, 205-206.

Yamamoto, K. R. \& Alberts, B. M. (1970). Rapid bacteriophage sedimentation in the presence of polyethylene glycol and its application to large-scale virus purification. Virology 40, 734-744. 